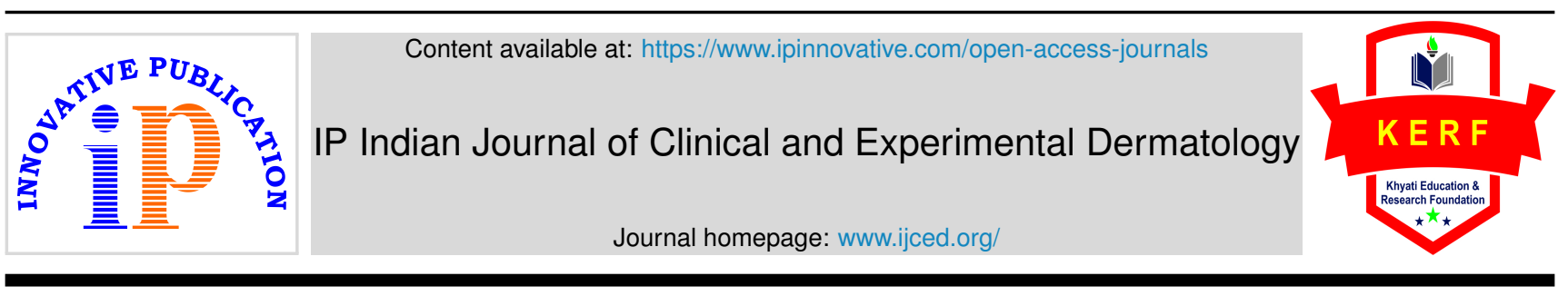

Original Research Article

\title{
A clinical study of pattern of geriatric dermatosis in tertiary care hospital of Rajasthan
}

\author{
Priyanka Meena ${ }^{1}$, Bajrang Soni ${ }^{1, *}$ \\ ${ }^{1}$ Dept. of Dermatology, Pandit Deen Dayal Upadhyay medical college, Churu, Rajasthan, India
}

\section{A R T I C L E I N F O}

\section{Article history:}

Received 12-05-2021

Accepted 17-05-2021

Available online 26-05-2021

\section{Keywords:}

Geriatric

Dermatosis

Aging

\begin{abstract}
A B S T R A C T
Introduction: Geriatric health care has received lot of attention nationwide due to increase in life expectancy over the time. Among the various health issue geriatric dermatosis are one of the most common reason for regular OPD visits. This study was done to inquest the spectrum of cutaneous manifestation and the factors responsible for causing physiological and pathological changes in the skin of elderly people. Material and Methods: Three hundred consecutive patients aged more than $60 \mathrm{yrs}$ of age attending the out patient department of dermatology at PDU Medical College \& hospitals Churu were subjected for study. A detailed history was taken. A complete general, systemic \& Cutaneous examination was done along with relevant investigation were carried out. Findings were collated in Performa for analysis and interpretation of data.

Results : A total of 300 patients were enrolled in the study out of which $59 \%$ were male and $41 \%$ were female. Pruritis was the commonest complain elicted in $68.5 \%$ of patients. Among the physiological changes xerosis was the commonest seen in $63 \%$ of patients and infecions followed by eczems was the common pathological conditions.

Conclusion: The population of $60 \mathrm{yrs}$ and above is a rapidly growing dermatology clientele with both physiological and pathological manifestations. This study highlights the various dermatoses peculiar to the geriatric population and aims at sensitizing the fraternity to the specific needs of this special age group.

(C) This is an open access article distributed under the terms of the Creative Commons Attribution License (https://creativecommons.org/licenses/by/4.0/) which permits unrestricted use, distribution, and reproduction in any medium, provided the original author and source are credited.
\end{abstract}

\section{Introduction}

The human integument, comprising one-sixth of the total bodyweight, is the most visible indicator of age. ${ }^{1}$ Aging is a complex multifactorial phenomenon in which progressive intrinsic changes in the skin combine synergistically with cumulative environment insults to produce both structural and functional disturbances. ${ }^{2}$

With aging the number of collagen and elastin fibers in the dermis decreases and total skin thickness decreases a result of flattening of the dermal papillae

at the epidermal-dermal junction. ${ }^{3}$ Although rarely fatal, cutaneous diseases carry with them significant morbidity and the potential to greatly decrease the patient's quality of

\footnotetext{
* Corresponding author.

E-mail address: pm420959@gmail.com (B. Soni).
}

life. $^{4}$

In India, there were 72 million elderly persons above 60 years of age as of 2001 and this number is likely to increase to 179 in 2031 and hence dermatologic care in geriatric population needs emphasis. ${ }^{5}$ This study gives an insight into different types of dermatological problems of the aged, their incidence, the various factors contributing to it and the association with systemic diseases. ${ }^{6}$

\section{Materials and Methods}

The study is cross -sectional observational study carried out on 300 patients aged 60 yrs and above attending the outpatient department of dermatology at PDU Medical college \& attach group of hospitals churu were enrolled in the study after meeting the inclusion criteria of age $60 \mathrm{yrs}$ and above of either sex. The exclusion criteria 
taken in account for the patients who did not give consent for examination. A detailed history of cutaneous complaints with comorbidity was taken. A complete general physical and systemic examination was carried out. Routine examination were carried out wherever it was necessary. Findings were collated in a master chart and results analyzed.

\section{Results}

Following observation were made in the study and the results analysed Total 300 patients above the age 60 yrs were studied of which $177(59 \%)$ were male and $123(41 \%)$ were females (figure 1). Maximum number of patients 182(61\%) belong to the age group of 60-69 years. The male to female ratio was 1 :

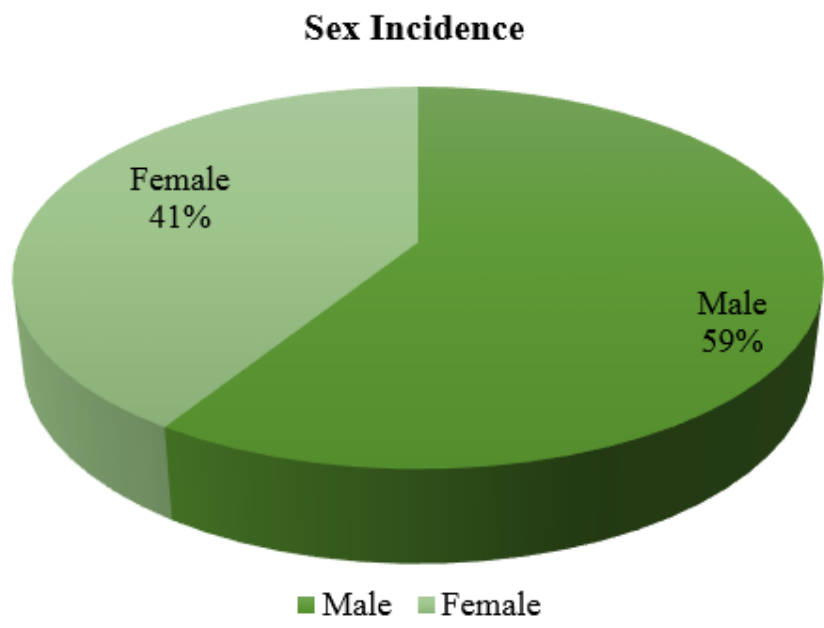

Fig. 1: Sex incidence

Pruritis was the commonest complaint seen in $68.5 \%$ of patients of which $15 \%$ of the patients had senile pruritis and the rest is associated with cutaneous dermatosis.

Xerosis $190(63 \%)$ were the most common physiological cutaneous manifestation seen in our study which is followed by wrinkling $74(24 \%)$. The physiological changes were described in table 1.

Among the systemic diseases diabetes (37\%) was found to have the highest incidence followed by hypertension $(19 \%)$ and coronary artery diseases $(19.35 \%)$ which had almost same incidence. These were tabulated in bar diagram.

Amongst the various pathological condition observed Infections and infestation were the most common dermatosis seen in $158(52.67 \%)$ followed by eczema $79(26.33 \%)$. Of various infections fungal infection was the commonest $51(17 \%)$ followed by viral $(14.67 \%)$, parasitic $(10.67 \%)$ and bacterial $(10.33 \%)$.

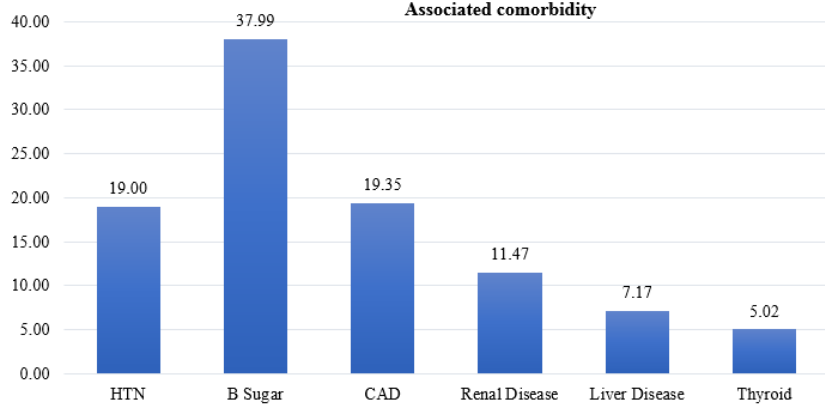

Fig. 2: Associated Comorbidities in geriatric population

A total of 79 patients $(26.33 \%)$ were found to have eczema in our study. Endogenous eczema were seen in 48 cases $(16 \%)$ \& exogenous eczema found in 31 cases $(10.33 \%)$. Among various type of endogenous eczema nummular eczema had the highest incidence with 29 patients $(9.67 \%)$ followed by prurigo simplex seen in 19 patients $(6.33 \%)$. Among exogenous eczema, allergic contact dermatitis had the highest incidence $14(4.67 \%)$ followed by irritant dermatitis seen in 11(3.67\%) patients.

Papulosquamous disoders were seen in 21 cases $(7 \%)$ in our study. 13 cases $(4.33 \%)$ were of psoriasis \& $8(2.67 \%)$ were of erythroderma.

Among miscellaneous conditions urticaria were seen in 9 cases $(3 \%)$. In autoimmune connective tissue disoders DLE seen in 3 cases (1\%). In pigmentary disoders 2 cases $(0.67 \%)$ of vitiligo was observed. Among benign tumour 28 cases $(9.33 \%)$ of seborrheic keratosis were seen . No case of malignant disoder were found in our study.

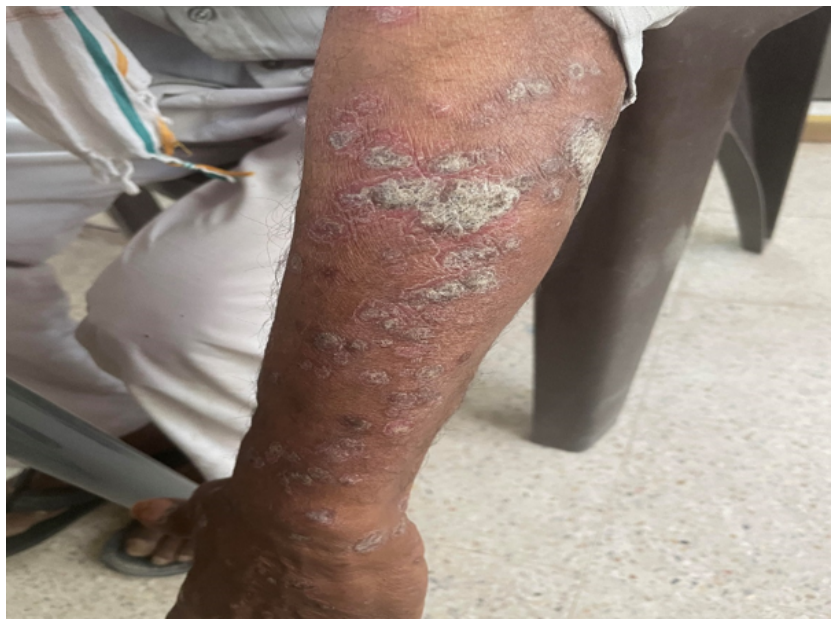

Fig. 3: Showing Psoriatic plaque 
Table 1: Physiological changes

\begin{tabular}{lllccccc}
\hline \multicolumn{2}{l}{$\begin{array}{l}\text { Physiological Changes } \\
\text { S.No }\end{array}$} & Male & Percentage & Female & Percentage & Total & Percentage \\
1 & Wrinkle & 33 & 11.00 & 41 & 15.30 & 74 & 24.67 \\
2 & Xerosis & 98 & 32.67 & 92 & 34.33 & 190 & 63.33 \\
3 & IGH & 7 & 2.33 & 3 & 1.12 & 10 & 3.33 \\
4 & S Purpura & 5 & 1.67 & 8 & 2.99 & 13 & 4.33 \\
5 & F Sole & 8 & 2.67 & 5 & 1.87 & 13 & 4.33 \\
& Total & 151 & & 149 & & 300 & 100.00 \\
\hline
\end{tabular}

Table 2: Distribution of cutaneous diseases in geriatric patients

\begin{tabular}{|c|c|c|c|}
\hline S. No. & Condition & No. of cases & Incidence $(\%)$ \\
\hline 1 & Infection & 158 & 52.67 \\
\hline \multirow[t]{3}{*}{$\mathrm{a}$} & Fungal & 51 & 17.00 \\
\hline & $\mathrm{TC}$ & 17 & 5.67 \\
\hline & Intertrigo & 27 & 9.00 \\
\hline \multirow[t]{2}{*}{$\mathrm{b}$} & Bacteria & 31 & 10.33 \\
\hline & Pyoderma & 31 & 10.33 \\
\hline \multirow[t]{3}{*}{$\mathrm{c}$} & Viral & 44 & 14.67 \\
\hline & H Zoster & 38 & 12.67 \\
\hline & EM & 13 & 4.33 \\
\hline \multirow[t]{2}{*}{ d } & Parasitic & 32 & 10.67 \\
\hline & Scabies & 32 & 10.67 \\
\hline 2 & Eczema & 79 & 26.33 \\
\hline \multirow[t]{3}{*}{$\mathrm{a}$} & Endogenous & 48 & 16.00 \\
\hline & N Eczema & 29 & 9.67 \\
\hline & Psimplex & 19 & 6.33 \\
\hline \multirow[t]{4}{*}{$\mathrm{b}$} & Endogenous & 31 & 10.33 \\
\hline & $\mathrm{ACD}$ & 14 & 4.67 \\
\hline & IED & 11 & 3.67 \\
\hline & PLE & 6 & 2.00 \\
\hline \multirow[t]{3}{*}{3} & P Disease & 21 & 7.00 \\
\hline & Psoriasis & 13 & 4.33 \\
\hline & Erythroderma & 8 & 2.67 \\
\hline \multirow[t]{2}{*}{4} & Others & 42 & 14.00 \\
\hline & Total & 300 & 100.00 \\
\hline
\end{tabular}

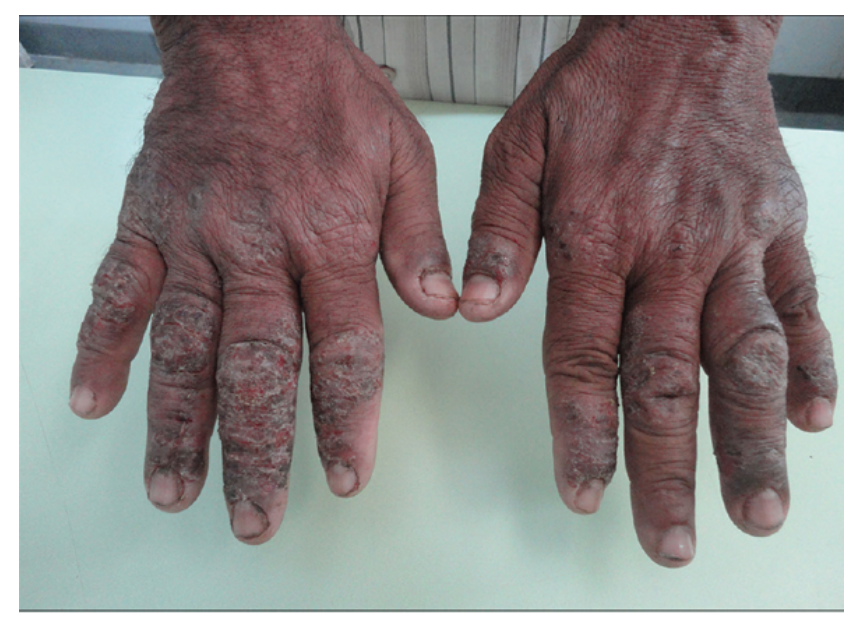

Fig. 4: Showing contact dermatitis in cement worker

\section{Discussion}

In our study we noticed various skin changes in elderly which occur either due to natural aging process, or due to pathological dermatological conditions. The skin findings were attributed by either cumulative sun exposure, associated co-morbid conditions or due to pathological conditions. Therefore the ambit of dermatological care needed for the elderly population is different from that for other age groups.

A total of 300 patients age 60 yrs and above were examined over a period of one year of which males out numbered females with female to male ratio 1:1.4. This is largely in tune with other studies. ${ }^{6-9}$ In a few studies female have outnumbered male patients. ${ }^{10,11}$ Maximum no of patients are in age group 60-69 yrs (61\%) which was similar to other studies. ${ }^{10-13}$ The oldest patient was $80 \mathrm{yrs}$ old. 
Pruritis was the commonest complaint seen in $68.5 \%$ of patients of which $15 \%$ of the patients had senile pruritis and the rest is associated with cutaneous dermatosis. Patange et al (6) noted pruritus in $78.5 \%$ of patients, of which $3.8 \%$ had senile pruritus and the rest were associated with cutaneous dermatoses $(91.1 \%)$. In all the studies, pruritus has been the commones complaint noted varying from $11.5 \%$ to 54 $\% .^{5,6,13,14}$

In our study among various comorbid conditions Diabetes Mellitus had the highest incidence of about $37 \%$. Diabetes as the most common co-morbidity also observed in studies. ${ }^{6,13,14}$ Hypertension [19\%] is the second most common systemic diseases seen in our study but in some studies it had the highest incidence. ${ }^{8,10}$ In present study coronary artery diseases cases were seen in $18 \%$ of geriatric population. Such higher incidence is not observed in any study showing the increasing trend of heart diseases in older age group.

There is a very thin line in deciding what is physiological and what is pathological in older person's skin. Many changes and lesions are normal, except occasionally in degree and number. In our study we consider Xerosis, wrinkling, senile purpura, fissured soles and idiopathic guttate hypomelanosis as physiological changes. Xerosis was the commonest physiological change seen in 190(63.33 $\%)$ patients in present study. Various studies had reported prevelance of xerosis between $7 \%$ to $99.6 \% .^{6-10,13}$ The high incidence could be attributed due to hot and dry climate of northern rajasthan as well as less use of emollients and usage of harsher soaps . Wrinkling seen in 74. (24.67\%) patients. Similar findings have been noted in other studies. Slight lower incidence of wrinkling in this study may be because of increase tolerance of racially pigmented skin Senile purpura noticed in $13(4.33 \%)$ of patients. Studies like grover et $\mathrm{al}^{10} \&$ raveendra et $\mathrm{al}^{8}$ reported higher incidence of senile purpura $10 \%$ and $15 \%$ respectively.

Infectious dermatosis was observed in $158(52.67 \%)$ of our study population. These results comparable with durai et al ${ }^{13}(46.8 \%)$, grover et al $^{10}(43.5 \%)$. this high incidence of infectious dermatosis in geriatric population of our study is mainly due to hot, humid climate of our place. Along with this Factors like poor hygiene, neglect, underlying disease like diabetes, bedridden status may also contribute to infections.

Among the infective disoders, fungal infections 51(17\%) was the common disorder in our study. Fungal infection were mainly represented by tinea corporis $(5.67 \%)$ is comparable with talukdar et al ${ }^{15}(7.2 \%)$. Viral infection $44(14.67 \%)$ were the next common infection followed by bacterial $(10.33 \%)$ and parasitic diseases $(10.67 \%)$. This is in unison with other studies. ${ }^{6-10,13,14}$

In our study $79(26.33 \%)$ patients were found to have eczema. These findings were comparible with durai et al $(24.2 \%)$. The total incidence of eczema in various studies ranges from $13.5 \%{ }^{6}$ to $58 \% .{ }^{4}$ Endogenous eczema found to have higher incidence (16\%) compare to exogenous eczema (10.33\%). This is may be due to elderly group of patient mainly remain indoor and is not expose to the external environment. Among endogenous eczema nummular eczema had the highest incidence with $9.67 \%$ cases. In exogenous eczema contact dermatitis was observed in $4.67 \%$. Both the findings are comparible with kshetrimayum $\mathrm{S}$ et $\mathrm{al}^{16}$ with $6 \%$ and $4.8 \%$ incidence respectively. Improper hygiene and decrease immunity are the precipitating factors for endogenous eczema. Moreover extreme hot climate, use of harsh soaps and lack of use of emmolients worsen the condition .

Papulosquamous disoders constituted (7\%) in the study population out of which psoriasis was common and found in $(4.33 \%)$ of study population. The incidence of papulosquamous disoders in present study is in concordance with the study of goyal et al ${ }^{17}$ with incidence $4 \%$. In our study erythroderma is found in $8(2.67 \%)$ cases which is comparible with study of Chopra A et al. ${ }^{18}$

Among benign skin tumour seborrheic keratosis was the most common type seen in 28 cases $(9.33 \%)$. However the incidence observed in our study is much lower as compared to other studies with incidence ranging from $23.3 \%$ to $56 \% .{ }^{8-10,15}$ No malignant condition were noted in this study. It is similar to the study by leena raveendra. This could be because of the lower incidence of skin cancers in racially pigmented skin.

In our study among autoimmune connective tissue disoders 3 cases $(1 \%)$ of discoid lupus erythematosus were seen which is similar to Agrawal et al. ${ }^{19}$

Pigmentary disoder were observed in 12 patients (4\%) of study population out of which idiopathic guttate hypomelanosis being the commonest seen in 10(3.33\%) cases. Sahoo et al ${ }^{14}$ found IGH in $(6.5 \%)$ cases.

\section{Conclusion}

Due to increase in life expectancy india had thus acquired the label of "an aging nation " with $7.7 \%$ of its population being more than 60 yrs and old ${ }^{20}$ The geriatric population is afflicted with a great many dermatology concerns , not only because of normal ageing process but the additional stressors acquired from the environment. A proper knowledge of the physiological and pathological skin changes in the elderly may aid the dermatologist in the better management of the cases and also help in controlling the extrinsic factors, which will be helpful in prevention of diseases in elderly .

\section{Source of Funding}

No financial support was received for the work within this manuscript. 


\section{Conflicts of Interest}

There are no conflicts of interest.

\section{References}

1. Yannas I. Tissue and organ regeneration in adults. New York: Springer-Verlag; 2001.

2. Beauregard S, Gilchrest B. A survey of skin problems and skin care regimens in the elderly. Arch Dermatol . 1987;123(12):1638-43. doi:-10)/archderm.123.12.1638

3. Farage MA, Miller KW, Elsner P, Maibach HI. Structural Characteristics of the Aging Skin: A Review. Cutan Ocul Toxicol.

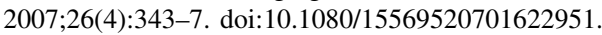

4. Liao YH, Chen KH, Tseng MP. Pattern of skin diseases in a geriatric patient group in Taiwan: a 7-year survey from the outpatient clinic of a university medical center. Dermatology. 2001;203(4):308-13.

5. Rajan SI, Sarma PS, Mishra US. Demography of Indian aging. $J$ Aging Soc Policy. 2001;15:11-30.

6. Patange VS, Fernandez RJ. A study of geriatric dermatoses. Ind J Dermatol Venerol Leprol. 1995;61:206-8.

7. Thapa DP, Jha AK, Kharel C, Shrestha S. Dermatological problems in geriatric patients: a hospital based study. Nepal Med Coll J. 2012;14:193-5.

8. Raveendra L. A clinical study of geriatric dermatoses. Our Dermatology Online. 2014;5(3):235-9. 10:10.724//0urd20143.59

9. Pavithra S, Shukla P, Pai GS. Cutaneous manifestations in senile skin in coastal Goa. NJDVL. 2010;9:1-6.

10. Grover S, Narasimhalu CRV. A clinical study of skin changes in geriatric population. Indian $J$ Dermatol Venereol Leprol. 2009;75(3):305-6. do: 10.4103/0378-6323.51266.

11. Kartal D, Çınar SL, Akın S, Ferahbaş A, Borlu M. Skin findings of geriatric patients in Turkey: A 5-year survey. Dermatol Sin. 2015;33(4):196-200. do1:10.1016/1.ds1.2015.04.001

12. Sheethal MP, Shashikumar BM. A cross-sectional study on the dermatological conditions among the elderly population in Mandya city. Int J Med Sci Public Health. 2015;4(4):467-70. doi:10.5455/1]msph.2015.2711201497.
13. Thappa DM, Durai PC, Kumari R, Malathi M. Aging in elderly: Chronological versus photoaging. Indian J Dermatol. 2012;57(5):343-52. 101:10.4103/0019-5154.100473.

14. Sahoo A, Singh PC, Pattnaik S, Panigrahi RK. Geriatric Dermatoses in Southern Orissa. Indian J Dermatol. 2000;45:66-74.

15. Talukdar K, Mitra D. A cross sectional observational study to evaluate various cutaneous manifestations in geriatric age group. Int J Med Res Rev. 2016;4(2):186-92.

16. Kshetrimayum S, Thokchom NV, Hafi N. Pattern of geriatric dermatoses at a tertiary care center in North-East India. Int J Res Dermatol. 2017;3(4):527.

doi: 10.18203 issn.24554529.intjresdermatol20175377.

17. Goyal A, Balai M, Mittal A, Khare AK, Gupta LK. Pattern of geriatric dermatoses at a Tertiary Care Teaching Hospital of South Rajasthan, India. Our Dermatol Online. 2017;8:237-41.

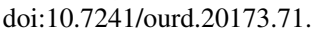

18. Chopra A. Skin diseases in the elderly. Indian J Dermatol Venereol Leprol. 1999;65:245-6.

19. Agarwal R, Sharma L, Chopra A, Mitra D, Saraswat N. A crosssectional observational study of geriatric dermatoses in a Tertiary Care Hospital of Northern India. Indian Dermatol Online J. 2019;10(5):524-9. do1:10.4103/1do1.1do]_282_18.

20. Nath A, Ingle G. Geriatric health in India: Concerns and solutions. Indian J Community Med. 2008;33(4):214-8. 10ن:10.4103/09700218.43225

\section{Author biography}

Priyanka Meena, Senior Resident

Bajrang Soni, Assistant Professor

Cite this article: Meena P, Soni B. A clinical study of pattern of geriatric dermatosis in tertiary care hospital of Rajasthan. IP Indian J Clin Exp Dermatol 2021;7(2):148-152. 